\title{
BbrizAGL6 Is Differentially Expressed During Embryo Sac Formation of Apomictic and Sexual Brachiaria brizantha Plants
}

\author{
Larissa Arrais Guimarães • Diva Maria de A. Dusi - Simona Masiero • \\ Francesca Resentini - Ana Cristina M. M. Gomes - Érica Duarte Silveira • \\ Lilian Hasegawa Florentino • Júlio Carlyle M. Rodrigues • Lucia Colombo • \\ Vera Tavares de C. Carneiro
}

Published online: 3 July 2013

(C) Springer Science+Business Media New York 2013

\begin{abstract}
Species of the genus Brachiaria comprise plants with different modes of reproduction, sexual and apomictic. In apomixis, the embryo sac differentiates from an unreduced cell, and the embryo develops in the absence of egg cell fertilisation. In this work, the characterisation and expression analyses of a MADS-box gene from Brachiaria brizantha, named BbrizAGL6, was described in sexual and apomictic plants. Phylogenetic analyses indicated that BbrizAGL6 belongs to the AGL6-like subfamily of proteins and clusters together with the AGL6-like protein of other monocots. BbrizAGL6 and AGL6 show conservation of the protein complex. Furthermore, BbrizAGL6 expressed preferentially
\end{abstract}

Electronic supplementary material The online version of this article (doi:10.1007/s11105-013-0618-8) contains supplementary material, which is available to authorized users.

L. A. Guimarães · D. M. de A. Dusi • A. C. M. M. Gomes •

É. D. Silveira • L. H. Florentino · J. C. M. Rodrigues •

V. T. de C. Carneiro $(\square)$

Embrapa Recursos Genéticos e Biotecnologia, Parque Estação

Biológica, PqEB-Av. W5 Norte (final), Caixa Postal 02372,

70770-917 Brasília, DF, Brazil

e-mail: vera.carneiro@embrapa.br

L. A. Guimarães • V. T. de C. Carneiro

Universidade de Brasília, Campus Universitário Darcy Ribeiro,

S/N-Asa Norte, Brasília, DF 70910-900, Brazil

S. Masiero $\cdot$ F. Resentini $\cdot$ L. Colombo

Dipartimento di Biologia, Università degli Studi di Milano,

Via Celoria 26, 20133 Milan, Italy

É. D. Silveira

Facultad de Ciencias Agrarias, Pontificia Universidad Catolica, Av.

Alicia Moreau de Justo 1300, C1107AAZ Buenos Aires, Argentina in reproductive tissues and corresponding transcripts were detected in anthers and ovules. In ovules of $B$. brizantha, where the main differences among sexual and apomictic reproduction occur, BbrizAGL6 was differentially modulated. Transcripts of BbrizAGL6 were localised in the megaspore mother cell of ovaries from apomictic and sexual plants and, additionally, in the region where aposporic initial cells differentiate, in the nucellus of apomictic plants. For the first time, a role of an AGL6-like gene in megasporogenesis of apomictic and sexual plants is suggested.

Keywords Apomixis - Arabidopsis $\cdot$ Brachiaria . MADS-box $\cdot$ Monocot $\cdot$ Plant reproduction

\section{Introduction}

The transition between haploid and diploid generations in the life cycle of angiosperms occurs in the ovule. The ovule is also the site of most of the processes relevant to sexual reproduction and to the asexual mode of reproduction through seeds, known as apomixis (Koltunow and Grossniklaus 2003). Sexual reproduction and apomixis diverge in two main steps: meiosis at megasporogenesis and fertilisation (Koltunow and Grossniklaus 2003). In sexual reproduction during the development of the megagametophyte, or embryo sac, after chromosome reduction by meiosis of the Megaspore Mother Cell (MMC), three megaspores degenerate and one functional megaspore is obtained. After three mitotic divisions and differentiation, a seven-celled embryo sac of the Polygonum-type is generated, consisting of: one egg cell, one central cell, two synergids and three 
antipodals. Upon double fertilisation, the egg cell and the central cell are fertilised by two spermatic cells, giving rise to the seed embryo and endosperm.

Apomixis is characterised by the omission of meiosis and egg cell fertilisation; it produces a progeny identical to the mother plant by autonomous development of the embryo from an unreduced egg cell. Gametophytic apomixis is classified into apospory or diplospory, depending on the origin of the cell that initiates unreduced embryo sac formation (Nogler 1984; Rodriguez-Leal and Vielle-Calzada 2012). Differentiation of the precursor cell from a MMC that failed to effect meiosis is called diplospory (Nogler 1984). Apospory, observed in Brachiaria, a tropical forage grass, is characterised by differentiation of multiple precursors from sporophytic cells, called aposporic initials (AI), in a position other than that occupied by the MMC (Asker and Jerling 1992; Dusi and Willemse 1999; Araujo et al. 2000). Simultaneously, in facultative apomixis, the MMC can form a reduced embryo sac by sexual mode of reproduction. Embryogenesis occurs autonomously without fertilisation of the egg cell in aposporic embryo sacs. Endosperm formation may be autonomous or may require fertilisation (pseudogamy) (Nogler 1984), as in Brachiaria (Alves et al. 2001). In Brachiaria the unreduced Panicumtype embryo sac differs morphologically from the reduced embryo sac, which is of the Polygonum-type. The Panicumtype embryo sac is composed of just four cells: two synergids, one egg cell and one central cell.

In sexual plants, the formation of the germ line is actively restricted in somatic cells by an epigenetic pathway (OlmedoMonfil et al. 2010, Singh et al. 2011). In aposporic apomictic plants, somatic cells can originate embryo sacs, thus, its origin is not restricted to the megasporocytes. However, the ability of somatic cells to form embryo sacs in aposporic plants depends on sexual pathway initiation, as shown in apomictic Hieracium, where $\mathrm{AI}$ appearance requires $\mathrm{MMC}$ and tetrad differentiation. These data suggest that an interaction between sporophyte and gametophyte is needed for apomixis (Koltunow et al. 2011). In Brachiaria brizantha, AIs are visualised surrounding intact or degenerating tetrads (Araújo et al. 2000). Isolating and characterising genes that are putatively related to the determination of sporophytic and gametophytic fates of the ovule in apomictic and sexual plants can contribute to understanding the molecular basis of these modes of reproduction. Gene expression information is being built in the female reproductive organs, where the main differences between apomictic and sexual plants occur (Pessino et al. 2001; Rodrigues et al. 2003; Polegri et al. 2010; Sharbel et al. 2010; Zhang et al. 2012). In B. brizantha, a differential pattern of expression in developing ovaries of apomictic and sexual plants was detected by macroarray analysis (Silveira et al. 2012). Among the genes expressed in ovaries a MADS-box gene similar to the AGL6 of Zea mays, BbrizAGL6, showed a differential pattern of gene expression in apomictic and sexual plants. This work aims to investigate the association among BbrizAGL6 expression and the main events of embryo sac differentiation.

MADS-box genes are transcription factors that are involved in all major aspects of plant development (Bowman et al. 1991; Coen and Meyerowitz 1991) including the differentiation of the cells of the ovule (Matias-Hernandez et al. 2010); for review, see Ng and Yanofsky (2001). MADS-box genes were extensively studied in gymnosperms and angiosperms including Eucalyptus globulus (Southerton et al. 1998), Nicotiana tabacum (Jang et al. 2002), Ginkgo biloba (Jager et al. 2003), Petunia hybrida (Vandenbussche et al. 2004), Alpinia hainanensis (Song et al. 2010), Coffea arabica (Oliveira et al. 2010), Gnetum gnemon (Wang et al. 2010), Prunus serotina (Liu et al. 2010), Brassica campestris (Liu et al. 2012a, b), Pyrus pyrifolia (Liu et al. 2012a, b) and Citrus (Hou et al. 2013). The MADS-box proteins are characterised by a highly conserved DNA binding domain, the MADS-box, which binds a consensus sequence named CArG box (Riechmann et al. 1996). Modulation of DNA-binding specificity and transcriptional activity is determined by the formation of complexes with other MADS proteins (Theissen and Saedler 2001). For instance, ovule identity is determined by a multimeric complex formed by the C-, D- and E-class MADSDomain factors, SEEDSTICK (STK), SHATTERPROOF1 (SHP1), SHP2 and SEPALLATA3 (SEP3), respectively (Favaro et al. 2003). Interactions between MADS-box proteins have been demonstrated to be conserved in monocot and eudicot plants (Favaro et al. 2002; de Folter et al. 2005). MADS-box transcription factors were extensively studied in various plant species and were able to form specific homodimers and heterodimers (de Folter et al. 2005). AGL6 from Arabidopsis and its homolog in rice, OsMADS6, have shown interaction with SEP-like, SQUAMOSA (SQUA) and AGL6 subfamilies (Moon et al. 1999, de Folter et al. 2005). The SEP subfamily is closely related to the AGAMOUS-LIKE6 (AGL6) and SQUA subfamilies (Favaro et al. 2002; de Folter et al. 2005; Zahn et al. 2005). In Petunia, AGL6 was able to interact with proteins that form multimeric complexes determining carpel and ovule identity such as SEP, AG and STK proteins (Rijpkema et al. 2009). Recently, it has been shown in Arabidopsis that VERDANDI, a gene from B3 superfamily, is a direct target for this complex, affecting the identity of antipodal and synergid cells. The evidence indicates that the MADS-box transcription factors are also involved in embryo sac ontogeny (Matias-Hernandez et al. 2010). The involvement of MADS-box genes in the differential development of apomictic plants has not been reported, apart from DEFICIENS in Hieracium (Guerin et al. 2000). In this work, we demonstrate that BbrizAGL6 is differentially expressed in apomictic and sexual $B$. brizantha ovules and is able to interact with those MADS-box proteins that regulate carpel and ovule identity. The involvement of this gene in the regulation of the apomictic pathway is discussed. 


\section{Materials and Methods}

\section{Plant Material}

Two accessions of B. brizantha (Syn. Urochloa brizantha) from Embrapa's germplasm collection were used in this work: BRA 002747 (B105), a sexual diploid $(2 n=2 x=18)$, and BRA 000591 (B030), a facultative apomictic tetraploid $(2 n=4 x=36)$ named B. brizantha $\mathrm{cv}$. Marandu, with up to $98 \%$ of apospory (Araújo et al. 2000). Both were cultivated in the field at Embrapa Genetic Resources and Biotechnology (Brasília, DF, Brazil). Ovaries from B. brizantha were previously classified in four different stages of development. Stages I and II correspond to megasporogenesis, while stages III and IV correspond to megagametogenesis (Araújo et al. 2000; Rodrigues et al. 2003). Reproductive structures and leaves were collected in the field, whilst roots were collected in the greenhouse.

\section{Amplification of a Brachiaria AGL6 Homologue}

A contig from an EST library of ovaries of $B$. brizantha (Silveira et al. 2012) with $83 \%$ to $95 \%$ similarity to the predicted proteins of ZAG3 and ZAG5 members of AGL6 clade (Mena et al. 1995) was used to design primers AG29F (5'-ATCGATCACCAGCAGGCAGAGAG-3') and AG1052 R (5'-CCACGCACACCACAATCACATAG-3') to amplify a AGL6 homologue. RNA extraction using TRIZOL ${ }^{\circledR}$ (Invitrogen $^{\mathrm{TM}}$ ) and cDNA amplification from a pool of ovaries at the four stages of development were performed as described previously (Rodrigues et al. 2003).

\section{Phylogenetic Analysis}

Phylogenetic analysis of 27 MADS-box protein sequences (Table S1) was conducted using MEGA 5 (Tamura et al. 2011) with default settings. The $K$ and $C$ terminal regions of MADS-box genes were used for the alignment using program ClustalW (Thompson 1994). The gap opening penalty was ten, and the gap extension penalty was 0.1 for pairwise alignments, and they were ten and 0.2, respectively, for multiple alignments. The Gonnet matrix was selected, and residue-specific and hydrophilic penalties were ON. The gap separation distance was four, and end gap separation was OFF. Phylogenetic tree was constructed using the neighbour-joining method (Saitou and Nei 1987). The bootstrap values (\%) of 1,000 replicates are shown at the branching points.

\section{Yeast Two-Hybrid Assays}

The two-hybrid assays were performed using the Ah109 Saccharomyces cerevisiae strain. $\mathrm{pBD}$ and $\mathrm{pAD}$ vector constructs were selected on yeast synthetic dropout (YSD) media lacking leucine (Leu) and tryptophan (Trp), respectively. Twohybrid interactions were assayed on two selective YSD media, the first lacking Leu, Trp and adenine, and the second lacking Leu, Trp and histidine (His) supplemented with 3aminotriazole at concentration $[5 \mathrm{mM}]$. Genes used for the yeast two-hybrid assays were cloned in the Gateway vector GAL4 system using vectors adapted from pADT7 (Clontech) for activation domain fusions and pGBKT7 (Clontech) for binding domain fusions passing through pDONOR207 (Life Technologies). The cDNA of the genes was amplified by polymerase chain reaction (PCR) with specific primers containing the attB1 and attB2 sequences for homologous recombination. Cloning of AG, SHP1, SHP2 and STK proteins in AD or BD vectors were previously described (Favaro et al. 2003). The SEP3 $\Delta 192$ cDNA fragment was amplified and cloned according to Brambilla and co-workers (Brambilla et al. 2007). The coding sequences of AGL6 and BbrizAGL6 containing the attB1 and attB2 sequences for homologous recombination were amplified using the following primers AtP3094 (5'-GGGGACAAGTTTGTACAAAAAAGCAGGCTCGATG GGAAGAGGGAGAGTG-3') and AtP3095 (5'-GGGGACC ACTTTGTACAAGAAAGCTGGGTGTCAAAGAACCCAACCTTGGACG-3') for AGL6 from Arabidopsis thaliana and AtP3139 (5'-GGGGACAAGTTTGTACAAAAAAGCAGGC TCCATGGGGAGGGGACGGGTC-3') and AtP3140 (5'-GG GGACCACTTTGTACAAGAAAGCTGGGTGTCAAAGAA CCCATCCCAGCATG-3') for BbrizAGL6 from B. brizantha.

\section{RT-qPCR}

RNA extraction from $B$. brizantha developing flowers was performed using TRIZOL ${ }^{\circledR}$ (Invitrogen ${ }^{\mathrm{TM}}$ ) as previously described (Rodrigues et al. 2003). RNA from leaves and roots was extracted using LiCL as previously described (Sambrook 2001). For the RNA extraction experiment, four pools of 1,000 ovaries and four pools of 50 anthers of each stage of pistil development were prepared. Ovaries and anther pools were prepared for apomictic and sexual B. brizantha. In addition, young leaves, root tissues and a pool of the whole spikelets containing a mixture of the corresponding four pistil developmental stages were isolated from both $B$. brizantha accessions.

Oligonucleotide pairs for BbrizAGL6, RT38F1 (5'TCTGCAAATCGGGTATCCTC-3') and RT38R1 (5'CCATCCCAGCATGAAGTTG-3') were designed using Primer 3.0 program (Rozen and Skaletsky 2000) with Tm of $60{ }^{\circ} \mathrm{C}$ and primer lengths between 19 and $20 \mathrm{bp}$. The reference gene used was BbrizUBCE, an ubiquitinconjugating enzyme, previously described as the best reference gene for these samples in B. brizantha (Silveira et al. 2009). PCR reactions were performed using Syber Green Rox Plus kit $\left(\mathrm{LGCBIO}^{\mathrm{TM}}\right)$ to detect dsDNA synthesis according to manufacturer's protocol. Reactions were run 
in a Mastercycler Realplex (Eppendorf ${ }^{\mathrm{TM}}$ ) device using the following cycling parameters $-95^{\circ} \mathrm{C}$ for $15 \mathrm{~min}$; 40 cycles of $95{ }^{\circ} \mathrm{C}$ for $15 \mathrm{~s}, 58{ }^{\circ} \mathrm{C}$ for $15 \mathrm{~s}, 72{ }^{\circ} \mathrm{C}$ for $20 \mathrm{~s}$. The dissociation curve was obtained by heating the amplicon from $60{ }^{\circ} \mathrm{C}$ to $95{ }^{\circ} \mathrm{C}$. No-template controls were included for each primer pair. Each amplicon was then analysed by electrophoresis on $1 \%$ agarose gel to verify the specificity of each amplification reaction. Two biological replicates for each of the samples were used for RT-qPCR analysis, and three technical replicates were analysed for each biological replicate. Relative gene expression was calculated using QGene software (Simon 2003).

\section{In Situ Hybridisation}

The RNA probe was synthesised using the DIG RNA labelling kit (Roche) according to the manufacturer's protocol. The same PCR fragment of $120 \mathrm{bp}$ from BbrizAGL6 amplified for RT-qPCR was cloned into pGEM-T Easy Vector System I (Invitrogen ${ }^{\mathrm{TM}}$ life technologies) and used as a template for in vitro transcription with SP6 and T7 polymerases, used as sense and antisense probes, respectively. In situ hybridisation was performed in sections of ovaries, at megasporogenesis and megagametogenesis and of anthers at microsporogenesis of the sexual and the apomictic accessions. In situ hybridisation was performed according to Alves et al. (2007). Sections were observed with a Zeiss Axiophot light microscope.

\section{Results}

BbrizAGL6 Shares High Sequence Similarity with AGL6 Isolated from Other Monocot Species

A sequence of $1,159 \mathrm{bp}$, similar to the predicted proteins of ZAG3 and ZAG5 members of AGL6 clade, was amplified from cDNA of ovaries of apomictic and sexual B. brizantha plants. This sequence, with an identical amino acid predicted sequence in sexual and apomictic plants, was named BbrizAGL6.

BbrizAGL6 shows two conserved motifs (I and II) in the C-terminal region, a typical feature of AGL6 clade members (Ohmori et al. 2009) (Fig. 1). The first motif is well conserved in monocots and represents a ten amino acid residue sequence, DCEPTLQIGY; however, in BbrizAGL6, glutamic acid is substituted by aspartic acid. The second motif is at the end of the C-terminal region and is composed of a ten amino acid residue sequence, ENNFMLGWVL.

Phylogenetic analyses have also proved that BbrizAGL6 belongs to the AGL6-like subfamily of proteins and clusters together with the AGL6-like protein of other monocots (Fig. 2).
BbrizAGL6 Interacts with Proteins that Form Ovule and Carpel Identity Complex in A. thaliana

To investigate whether BbrizAGL6 is able to interact with MADS-box proteins related to ovule and carpel identity, a GAL4-based yeast two-hybrid experiment was performed between BbrizAGL6 and A. thaliana MADS-box proteins, those that determine ovule and carpel identity. AG, SHP1 and SHP2 are members of the C-class; the D class STK and SEP $3 \Delta 192$ from E-class were tested. A deleted version of SEP3 was used since the full protein auto-activates the reporter gene (Brambilla et al. 2007). Analyses proved that BbrizAGL6 homodimerises and heterodimerises with AG, SHP1, SHP2 and STK. However, BbrizAGL6 interacted with SHP1, SHP2 and STK only when BbrizAGL6 coding sequence was fused to the activation domain (AD), and SHP1, SHP2 and STK to the binding domain (BD) (Table 1). None of the proteins tested were able to interact with empty vector $\mathrm{AD}$ or $\mathrm{BD}$ when the transformed yeast was grown in media lacking Trp, Leu and His, supplemented with $5 \mathrm{mM} \mathrm{3-aminotriazole.}$

\section{BbrizAGL6 Is Sporophytically Expressed in Flowers}

The pattern of BbrizAGL6 expression in apomictic and sexual $B$. brizantha was firstly investigated by RT-qPCR in reproductive and vegetative structures (Fig. 3). Expression of BbrizAGL6 was restricted to the reproductive tissues; the strongest signal being observed in ovaries. Ovaries from sexual plants showed higher expression compared with those of apomictic plants. The highest BbrizAGL6 expression was observed at stage II, corresponding to ovules at megasporogenesis (Dusi and Willemse 1999; Araújo et al. 2000). In developing anthers, BbrizAGL6 expression was lower compared with developing ovules.

In situ hybridisation analysis was performed to investigate in detail the spatial and temporal pattern of BbrizAGL6 expression. During microsporogenesis, hybridisation signal was stronger in pollen mother cells (PMC) and lower in the tapetum cells (Fig. 4a, d). Transcripts of BbrizAGL6 were localised in the MMC of ovaries from apomictic and sexual plants (Fig. 4b, c, e, f). In apomictic plants, expression was also present in the nucellus surrounding the MMC (Fig. 4b, c). During megagametogenesis, BbrizAGL6 expression decreased in the ovaries of apomictic and sexual plants (Fig. $4 \mathrm{~g}$, h). Control in situ hybridisation with a BbrizAGL6 sense probe confirmed that the probe employed is specific since we could not record any signals (Fig. 4i, j).

\section{Discussion}

Knowledge about molecular pathways involved in different types of reproduction in flowering plants is still elusive. MADS-box genes are much conserved among living organisms 


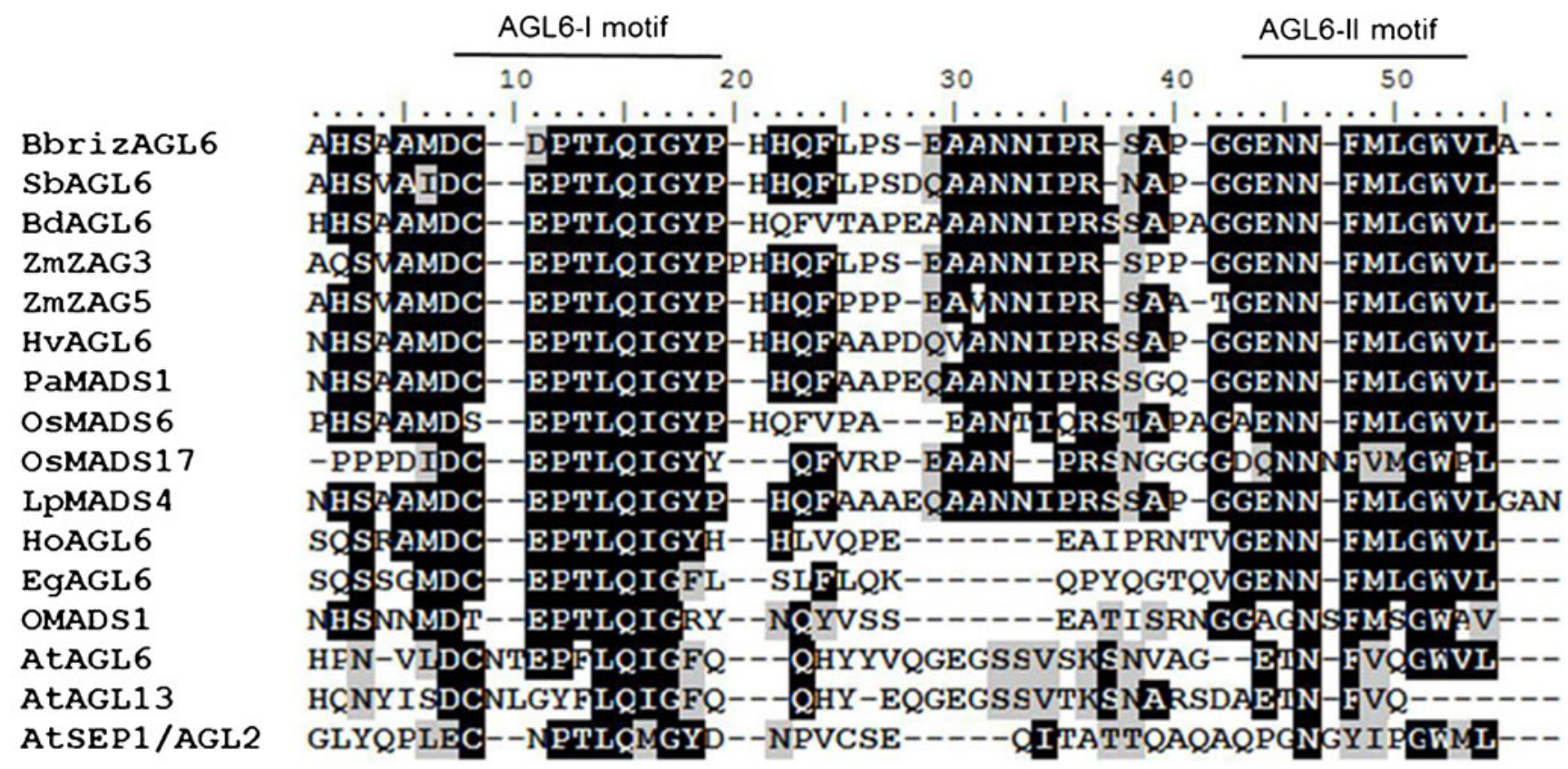

Fig. 1 Alignment of C-terminal region of AGL6-like MADS-box proteins. The C-terminal regions of 15 AGL6-like MADS-box proteins from various monocot plant species and from Arabidopsis were used (see Supplemental Table 1) Arabidopsis SEP-like protein (at SEP1/AGL2)

(Purugganan et al. 1995). They are widely studied in plants, contributing to the explanation of various aspects related to floral organ formation. This work sheds light on the involvement of MADS-box genes in apomictic and sexual reproduction, since they are poorly described in apomictic plants.

MADS-box transcription factors classified as MIKC are exclusive to plants and are composed of a MADS (M-), intervening (I-), keratin-like (K-) and C-terminal (C-) domain (Theissen et al. 1996). The MADS-domain is responsible for DNA binding. $\mathrm{K}$ domain mediates interactions, specified by I-domain, between other MIKC-type proteins (Davies and Schwarz-Sommer 1994). The Cterminal domain is the most divergent among different MADS-box genes but displays conserved motifs among members of the same clade (Davies and Schwarz-Sommer 1994), determining their divergent biological functions and possibly forming a specific network of interactions (Egea-Cortines et al. 1999; Honma and Goto 2001). BbrizAGL6 shows two motifs that are similar to those previously described in different species, especially among monocots (Zahn et al. 2005) and which resemble SEP proteins. This region is known to be essential for protein-protein interaction and transcriptional activation (Honma and Goto 2001). The AGL6-I and AGL6-II motifs were described in rice as transcriptional activation domains, and the AGL6-II has stronger activity than the AGL6-I one (Ohmori et al. 2009). Replacing the glutamic sequence was inserted in the alignment for the identification and comparison of the motifs. The positions of two conserved motifs are indicated above the sequences. Identical and similar amino acids are shaded black and grey, respectively. Analyses were done using ClustalW program

acid, found in the other monocot sequences, with aspartic acid, in the first motif of BbrizAGL6, might not be relevant as both are polar and negative amino acids. The BbrizAGL6 second motif is an acidic-rich domain and is identical to the AGL6-II motif identified in maize. The negative charge in this motif is critical for the structure of activation domain (Ohmori et al. 2009).

Phylogenetic analysis indicated that the predicted amino acid sequence of BbrizAGL6 is grouped together with AGL6 from other monocot species and is close to the SEP group, which is highly conserved among various plant species (Reinheimer and Kellogg 2009). BbrizAGL6 can be included in the same clade formed by ZAG3 and ZAG5 from maize, OsMADS6 from rice and SbAGL6 from sorghum. AGL6-like genes from grasses were shown to be expressed in paleas, lodicules, ovules and floral meristems and show a SEPALLATA-like function (Reinheimer and Kellogg 2009, Li et al. 2011). It was demonstrated that $A G L 6$ has a role in the formation of floral organs in monocots and eudicots (Viaene et al. 2010).

Studies in various plants indicated AGL6's ability to form multimeric complexes with MADS-box transcription factors related to ovule and carpel identity, similarly to SEP (Moon et al. 1999, de Folter et al. 2005). SHP1 and SHP2, related to the shattering of dehiscent fruits (Liljegren et al. 2000), act redundantly with STK in Arabidopsis ovules (Pinyopich et al. 2003) being grouped in an AG monophyletic group (Parenicova et al. 2003). BbrizAGL6 interaction with 


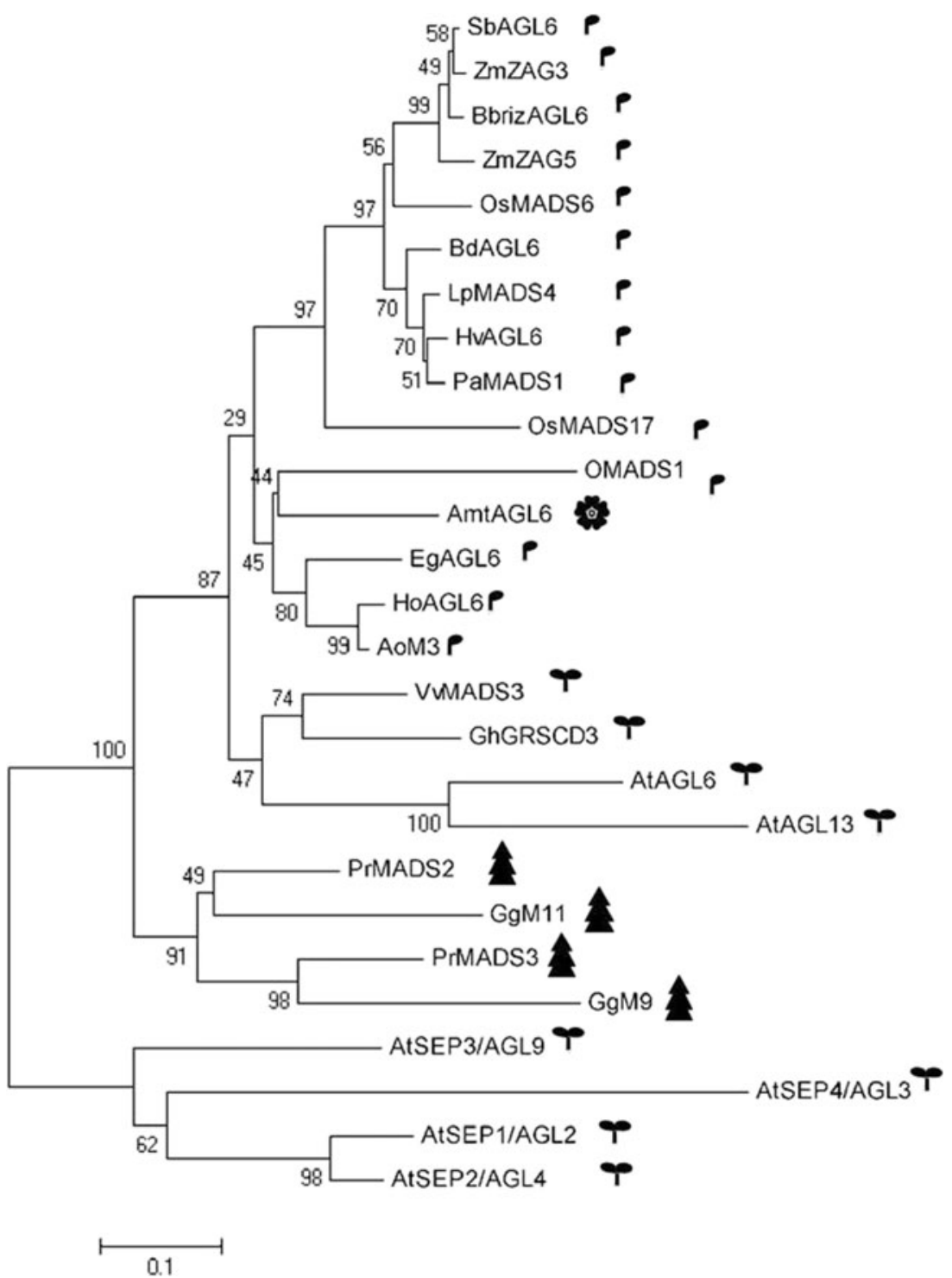

Fig. 2 Phylogenetic tree of MADS-box proteins constructed by the neighbour-joining method using 27 MADS-box protein sequences (see Supplementary Table S1). The bootstrap values (\%) of 1,000 replicates are shown at the branching points. $\boldsymbol{P} \boldsymbol{P}$ represent eudicot, monocot, magnoliid and gymnosperm, respectively

Table 1 Yeast two-hybrid study using the GAL4 system for testing interactions of BbrizAGL6 with other MADS-box proteins: AG, SHP1, SHP2, STK, AGL6 and SEP3 $\Delta$

\begin{tabular}{|c|c|c|c|c|c|c|c|}
\hline \multirow[t]{2}{*}{ BbrizAGL6 } & \multicolumn{3}{|c|}{ C-class } & \multirow{2}{*}{$\begin{array}{l}\text { D-class } \\
\text { STK }\end{array}$} & \multicolumn{3}{|l|}{ E-class } \\
\hline & $\mathrm{AG}$ & SHP1 & SHP2 & & AGL6 & SEP3 $\triangle$ & BbrizAGL6 \\
\hline$-W-L-A^{a}$ & $+\mathrm{a}$ & $+\mathrm{a}$ & $+\mathrm{a}$ & $+\mathrm{a}$ & $-\mathrm{b}$ & $+\mathrm{a}$ & - \\
\hline$-\mathrm{W}-\mathrm{L}-\mathrm{H}^{\mathrm{b}}$ & + & - & - & - & ++ & ++ & + \\
\hline
\end{tabular}

${ }^{a}$ Selective dropout medium lacking Trp, Leu and adenine (-W-L-A)

${ }^{\mathrm{b}}$ Selective dropout medium lacking Trp, Leu and His (-W-L-H) supplemented with 3-aminotriazole at concentration [5 mM]

++ Interactions clear in both directions, + interactions positive only in one direction, - no growth, $a$ interactions could only be tested in one direction due to autoactivation of the GAL4 reporter gene by intrinsic transcription activation domain, $b$ interactions could not be tested due to autoactivation of the GAL4 reporter gene by intrinsic transcription activation domain 


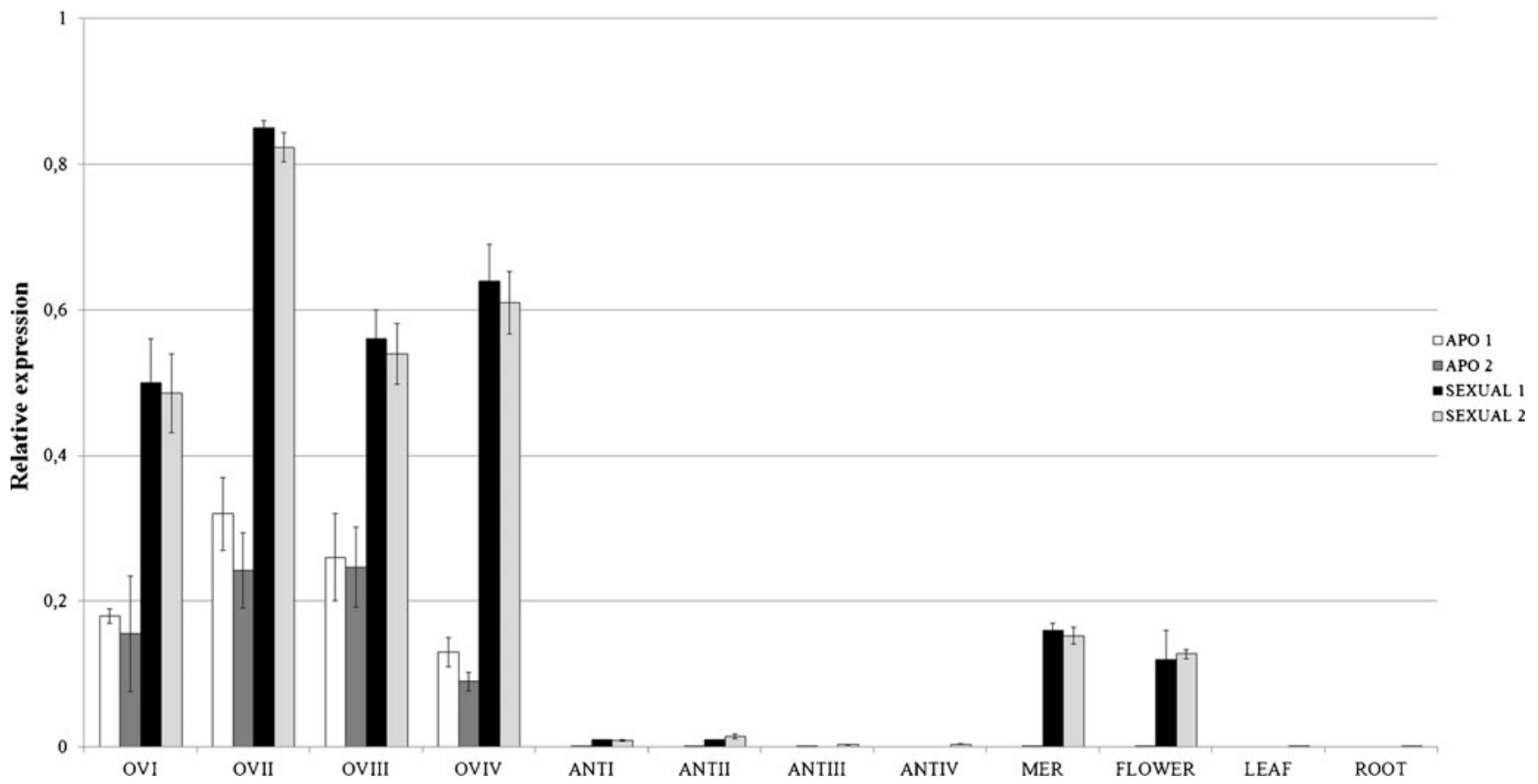

Fig. 3 Expression profile of BbrizAGL6 by RT-qPCR in ovaries in megasporogenesis (ovI, ovII) and megagametogenesis (ovIII, ovIV); anthers in microsporogenesis (ANTI, ANTII) and microgametogenesis (ANTIII, ANTIV); inflorescence meristem (MER); flower; leaf and root from apomictic and sexual plants. White and black columns represent first biological replicate from apomictic (APO 1) and sexual (SEXUAL 1)

plants, respectively. Dark and light grey columns represent second biological replicate from apomictic (APO 2) and sexual (SEXUAL 2) plants, respectively. Bars represent the standard error of technical variation. BbrizAGL6 is more expressed in sexual plants than in apomictic plants, especially in ovaries. Higher BbrizAGL6 expression was detected in sexual ovII; the stage where MMC starts its development

SHP1, SHP2 and STK can be due to its SEP-like function since SEP3 gene was designated as glue in the formation of the multimeric complex in Arabidopsis (Immink et al. 2009). This multimeric complex can be related to Brachiaria reproduction, since BbrizAGL6 is modulated in apomictic and sexual plants.

Yeast two-hybrid of OsMADS6, a rice AGL6 homolog, did not show any interaction with $\mathrm{B}$ and $\mathrm{C}$ class of MADS-box. Moreover, it was recently demonstrated that OsMADS6 is a key regulator of transcription levels of B-, C- and E-class genes ( $\mathrm{Li}$ et al. 2011). However, ZAG3 from maize showed interaction with $\mathrm{C}$ class of MADS-box genes (Moon et al. 1999; Thompson et al. 2009), results similar to that observed with BbrizAGL6. Interestingly, the rice AGL6-II motif is slightly different from those of BbrizAGL6 and ZAG3, which are identical. Analysis using yeast two-hybrid demonstrated that BbrizAGL6 has the same role as AGL6 from Arabidopsis and as observed in the literature with maize. AGL6 belongs to MIKC MADS-box type genes. Generally, genes from this group are expressed only in diploid tissues that control various aspects of sporophyte development. They are involved in almost all levels of the regulatory network that controls reproductive development. Some of them are affected by stress treatment regulating flowering time (Gramzow and Theissen 2010).

The expression of BbrizAGL6 in the ovary during megasporogenesis of sexual $B$. brizantha is consistent with data obtained in other species.

In Arabidopsis, rice and maize, AGL6 expression is more abundant in ovule sporophytic tissues, and its expression is restrained to flower organ (Mena et al. 1995; Ohmori et al. 2009; Reinheimer and Kellogg 2009; Koo et al. 2010). In rice, $A G L 6$ mRNA was strongly detected in MMC and microspores (Zhang et al. 2010). The peak of expression of BbrizAGL6, observed at stage II ovaries of apomictic and sexual plants, could be related to events that are more recurrent in this stage, such as meiosis. The localisation of expression at this stage was preferentially detected inside MMC and PMC, cells which will enter meiosis. Remarkably, in apomictic plants, a broader expression of BbrizAGL6 included the nucellar region near the MMC, where AI cells differentiate to form unreduced embryo sacs. These data suggest a deregulation of the spatial expression pattern of $A G L 6$ during sporogenesis of apomictic plants. It is possible that the presence of AGL6 in the nucellar region of apomictic plants enables AI formation; alternatively, AGL6 could mark the differentiation of sporogenous cells, either the MMC in sexual plants, or the AI precursor cells in apomictic plants, suggesting that the expression of BbrizAGL6 could be involved at sporogenesis, regardless of mode of reproduction. 

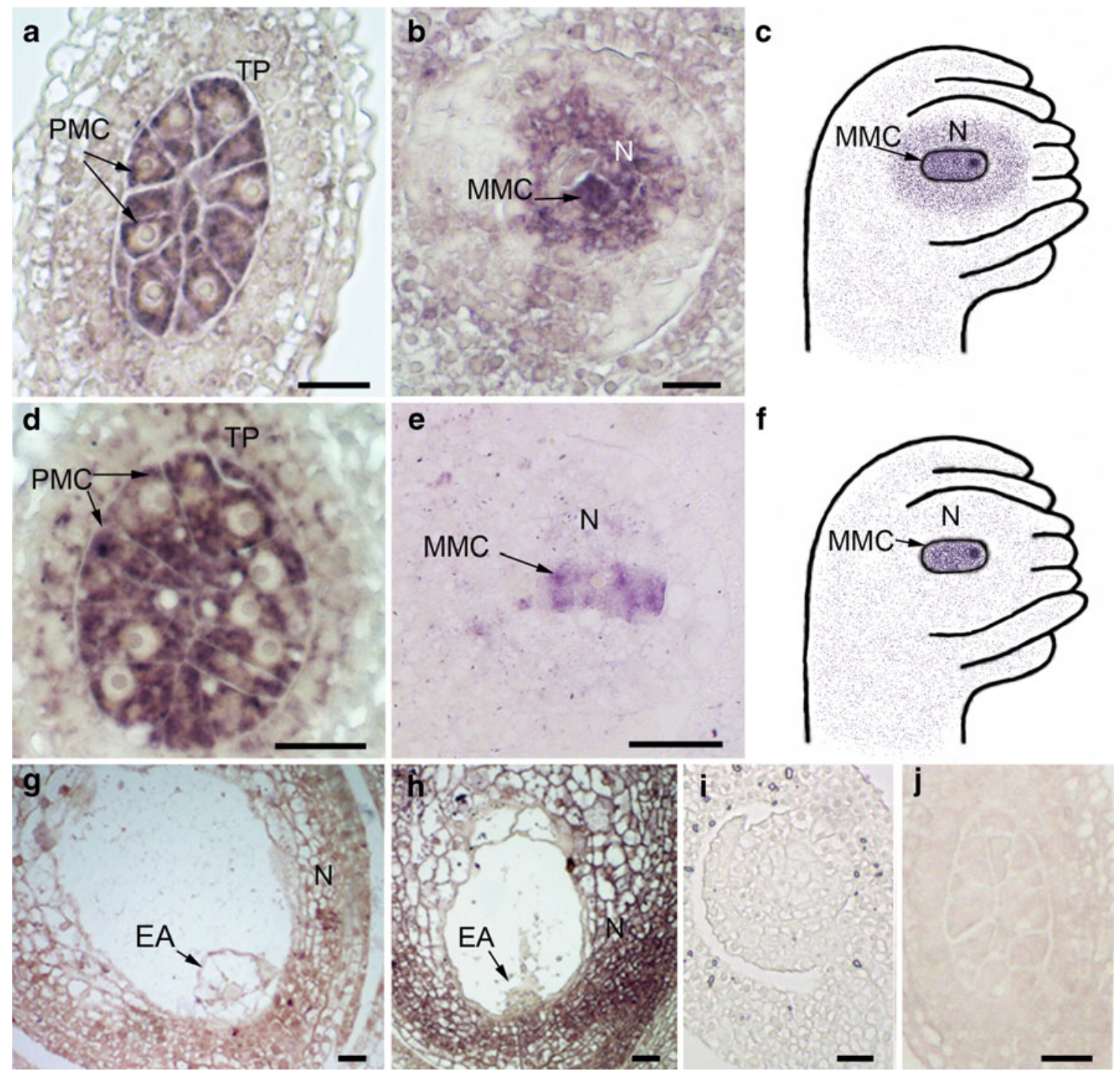

Fig. 4 Detection of BbrizAGL6 transcripts by in situ hybridisation in semi-thin sections of anthers $(\mathbf{a}, \mathbf{d})$ and ovaries $(\mathbf{b}, \mathbf{e}, \mathbf{g}, \mathbf{h})$ of apomictic $(\mathbf{a}, \mathbf{b}, \mathbf{g})$ and of sexual $(\mathbf{d}, \mathbf{e}, \mathbf{h})$ B. brizantha. Schematic representation of in situ hybridisation at megasporogenesis of apomictic (c) and sexual (f)

plants. Hybridisation of sense probe in ovary (i) and anther (j) of apomictic $B$. brizantha. EA, egg apparatus; $M M C$, megaspore mother cell; $N$, nucellus; $P M C$, pollen mother cell; $T P$, tapetum. Bar $=20 \mu \mathrm{m}$

The presence of $A G L 6$ in male sporogenous cells of sexual and apomictic $B$. brizantha, also observed in rice (Zhang et al. 2010), suggests that the latter is most likely the case.

Based on in situ analysis showing that $A G L 6$ is not present in gametophytic cells in rice (Zhang et al. 2010) and $B$. brizantha sexual and apomictic plants (this paper), this could be a conserved element in $A G L 6$ regulation, regardless of mode of reproduction. Therefore, AGL6 appears to be required not only for sexual reproduction but also for the apomictic process. This corroborates the hypothesis that apomixis is a consequence of deregulation of the sexual pathway (Koltunow and Grossniklaus 2003; RodriguezLeal and Vielle-Calzada 2012).

We have successfully cloned and characterised a MADS-box gene, BbrizAGL6, from B. brizantha plants. The phylogenetic association with MADS-box genes of other monocots was shown. In ovaries, BbrizAGL6 was expressed only in the MMC of sexual plants while in apomictic plants it was expressed more broadly in the MMC and surrounding cell types. BbrizAGL6 can be a useful marker for the characterisation and study of apomixis in Brachiaria.

Acknowledgements The authors acknowledge Ana L.M. Lacerda and Andrea D. Koehler for technical help in RNA extraction and Flávia S. Ferreira for dissecting ovaries. This work was supported by the National Council for Scientific and Technological Development-CNPq (490749/20089-VTCC) and the Brazilian Agricultural Research Corporation-Embrapa (0209020010.000- VTCC). This work is part of LAG's PhD thesis from Pós-Graduação em Biologia Molecular, University of Brasilia-UnB, Brazil, with a partial fellowship from CNPq and Embrapa. CNPq also provided a 1year fellowship for LAG at Università degli Studi di Milano, Italy. 


\section{References}

Alves ER, Carneiro VTC, Araujo ACG (2001) Direct evidence of pseudogamy in an apomictic Brachiaria brizantha (Poaceae). Sex Plant Reprod 14:207-212

Alves ER, Carneiro VTC, Dusi DMA (2007) In situ localization of three cDNA sequences associated with the later stages of aposporic embryo sac development of Brachiaria brizantha. Protoplasma 231:161-171

Araujo ACG, Mukhambetzhanov S, Pozzobon MT, Santana EF, Carneiro VTC (2000) Female gametophyte development in apomictic and sexual Brachiaria brizantha (Poaceae). Rév de Cytol Biol Végétales - Le Botaniste Tome 23:13-28

Asker SE, Jerling L (1992) Apomixis in plants. Boca Raton, Florida, USA: CRC Press, Inc 298 p

Bowman JL, Smyth DR, Meyerowitz EM (1991) Genetic interactions among floral homeotic genes of Arabidopsis. Development 112:1-20

Brambilla V, Battaglia R, Colombo M, Masiero S, Bencivenga S, Kater MM, Colombo L (2007) Genetic and molecular interactions between BELL1 and MADS box factors support ovule development in Arabidopsis. Plant Cell 19:2544-2556

Coen ES, Meyerowitz EM (1991) The war of the whorls: genetic interactions controlling flower development. Nature 353:31-37

Davies B, Schwarz-Sommer Z (1994) Control of floral organ identity by homeotic MADS-box transcription factors. Results Probl Cell Differ 20:235-258

de Folter S, Immink RG, Kieffer M, Parenicova L, Henz SR, Weigel D, Busscher M, Kooiker M, Colombo L, Kater MM, Davies B, Angenent GC (2005) Comprehensive interaction map of the Arabidopsis MADS box transcription factors. Plant Cell 17:1424-1433

Dusi DMA, Willemse MTM (1999) Apomixis in Brachiaria decumbens Stapf: gametophytic development and reproductive calendar. Acta Biol Cracov Ser Bot 41:151-162

Egea-Cortines M, Saedler H, Sommer H (1999) Ternary complex formation between the MADS-box proteins SQUAMOSA, DEFICIENS and GLOBOSA is involved in the control of floral architecture in Antirrhinum majus. EMBO J 18:5370-5379

Favaro R, Immink RG, Ferioli V, Bernasconi B, Byzova M, Angenent GC, Kater M, Colombo L (2002) Ovule-specific MADS-box proteins have conserved protein-protein interactions in monocot and dicot plants. Mol Genet Genomics 268:152-159

Favaro R, Pinyopich A, Battaglia R, Kooiker M, Borghi L, Ditta G, Yanofsky MF, Kater MM, Colombo L (2003) MADS-box protein complexes control carpel and ovule development in Arabidopsis. Plant Cell 15:2603-2611

Gramzow L, Theissen G (2010) A hitchhiker's guide to the MADS world of plants. Genome Biol 11:214

Guerin J, Rossel JB, Robert S, Tsuchiya T, Koltunow AMG (2000) A DEFICIENS homologue is down-regulated during apomictic initiation in ovules of Hieracium. Planta 210:914-920

Honma T, Goto K (2001) Complexes of MADS-box proteins are sufficient to convert leaves into floral organs. Nature 409:525-529

Hou X-J, Liu S-R, Khan M, Hu C-G, Zhang J-Z (2013) Genome-wide identification, classification, expression profiling, and SSR marker development of the MADS-box gene family in Citrus. Plant Mol Biol Rep 1-14

Immink R, Tonaco I, de Folter S, Shchennikova A, van Dijk A, Busscher-Lange J, Borst J, Angenent G (2009) SEPALLATA 3: the 'glue' for MADS box transcription factor complex formation. Genome Biol 10:R24

Jager M, Hassanin A, Manuel M, Le Guyader H, Deutsch J (2003) MADS-box genes in Ginkgo biloba and the evolution of the AGAMOUS family. Mol Biol Evol 20:842-854

Jang S, An K, Lee S, An G (2002) Characterization of tobacco MADSbox genes involved in floral initiation. Plant Cell Physiol 43:230 238
Koltunow AMG, Grossniklaus U (2003) Apomixis: a developmental perspective. Ann Rev Plant Biol 54:547-574

Koltunow AMG, Johnson SD, Rodrigues JCM, Okada T, Hu Y, Tsuchiya T, Wilson S, Fletcher P, Ito K, Suzuki G, Mukai Y, Fehrer J, Bicknell RA (2011) Sexual reproduction is the default mode in apomictic Hieracium subgenus Pilosella, in which two dominant loci function to enable apomixis. Plant J 66:890-902

Koo SC, Bracko O, Park MS, Schwab R, Chun HJ, Park KM, Seo JS, Grbic V, Balasubramanian S, Schmid M, Godard F, Yun D-J, Lee SY, Cho MJ, Weigel D, Kim MC (2010) Control of lateral organ development and flowering time by the Arabidopsis thaliana MADS-box Gene AGAMOUS-LIKE6. Plant J 62:807-816

Li H, Liang W, Hu Y, Zhu L, Yin C, Xu J, Dreni L, Kater MM, Zhang D (2011) Rice MADS6 interacts with the floral homeotic genes SUPERWOMAN1, MADS3, MADS58, MADS13, and DROOPING LEAF in specifying floral organ identities and meristem fate. Plant Cell 23:2536-2552

Liljegren SJ, Ditta GS, Eshed Y, Savidge B, Bowman JL, Yanofsky MF (2000) Shatterproof MADS-box genes control seed dispersal in Arabidopsis. Nature 404:766-770

Liu X, Anderson J, Pijut P (2010) Cloning and characterization of Prunus serotina AGAMOUS, a putative flower homeotic gene. Plant Mol Biol Rep 28(2):193-203

Liu T, Li Y, Zhang C, Qian Y, Wang Z, Hou X (2012a) Overexpression of FLOWERING LOCUS C, isolated from non-heading Chinese cabbage (Brassica campestris ssp. chinensis Makino), influences fertility in Arabidopsis. Plant Mol Biol Rep 30:1444-1449

Liu Y, Kong J, Li T, Wang Y, Wang A, Han Z (2012b) Isolation and characterization of an APETALA1-like gene from pear (Pyrus pyrifolia). Plant Mol Biol Rep 1-9

Matias-Hernandez L, Battaglia R, Galbiati F, Rubes M, Eichenberger C, Grossniklaus U, Kater MM, Colombo L (2010) VERDANDI is a direct target of the MADS domain ovule identity complex and affects embryo sac differentiation in Arabidopsis. Plant Cell 22:1702-1715

Mena M, Mandel MA, Lerner DR, Yanofsky MF, Schmidt RJ (1995) A characterization of the MADS-box gene family in maize. Plant $\mathrm{J}$ $8: 845-854$

Moon YH, Kang HG, Jung JY, Jeon JS, Sung SK, An G (1999) Determination of the motif responsible for interaction between the rice APETALA1/AGAMOUS-LIKE9 family proteins using a yeast two-hybrid system. Plant Physiol 120:1193-1204

Ng M, Yanofsky MF (2001) Function and evolution of the plant MADS-box gene family. Nat Rev Genet 2:186-195

Nogler GA (1984) Gametophytic apomixis. In: Johri BM (ed) Embriology of angiosperms. Springer-Verlag, Berlin, pp 475-518

Ohmori S, Kimizu M, Sugita M, Miyao A, Hirochika H, Uchida E, Nagato Y, Yoshida H (2009) MOSAIC FLORAL ORGANS1, an $A G L 6$-Like MADS box gene, regulates floral organ identity and meristem fate in rice. Plant Cell 21:3008-3025

Oliveira R, Chalfun-Junior A, Paiva L, Andrade A (2010) In silico and quantitative analyses of MADS-Box genes in Coffea arabica. Plant Mol Biol Rep 28(3):460-472

Olmedo-Monfil V, Duran-Figueroa N, Arteaga-Vazquez M, DemesaArevalo E, Autran D, Grimanelli D, Slotkin RK, Martienssen RA, Vielle-Calzada J-P (2010) Control of female gamete formation by a small RNA pathway in Arabidopsis. Nature 464:628-632

Parenicova L, de Folter S, Kieffer M, Horner DS, Favalli C, Busscher J, Cook HE, Ingram RM, Kater MM, Davies B, Angenent GC, Colombo L (2003) Molecular and phylogenetic analyses of the complete MADS-box transcription factor family in Arabidopsis: new openings to the MADS world. Plant Cell 15:1538-1551

Pessino SC, Espinoza F, Martinez EJ, Ortiz JP, Valle EM, Quarin CL (2001) Isolation of cDNA clones differentially expressed in flowers of apomictic and sexual Paspalum notatum. Hereditas 134:3542 
Pinyopich A, Ditta GS, Savidge B, Liljegren SJ, Baumann E, Wisman E, Yanofsky MF (2003) Assessing the redundancy of MADS-box genes during carpel and ovule development. Nature 424:85-88

Polegri L, Calderini O, Arcioni S, Pupilli F (2010) Specific expression of apomixis-linked alleles revealed by comparative transcriptomic analysis of sexual and apomictic Paspalum simplex Morong flowers. J Exp Bot 61:1869-1883

Purugganan MD, Rounsley SD, Schmidt RJ, Yanofsky MF (1995) Molecular evolution of flower development: diversification of the plant MADS-box regulatory gene family. Genetics 140:345-356

Reinheimer R, Kellogg EA (2009) Evolution of AGL6-like MADS box genes in grasses (Poaceae): ovule expression is ancient and palea expression is new. Plant Cell 21:2591-2605

Riechmann JL, Krizek BA, Meyerowitz EM (1996) Dimerization specificity of Arabidopsis MADS domain homeotic proteins APETALA1, APETALA3, PISTILLATA, and AGAMOUS. Proc Natl Acad Sci U S A 93:4793-4798

Rijpkema AS, Zethof J, Gerats T, Vandenbussche M (2009) The petunia $A G L 6$ gene has a SEPALLATA-like function in floral patterning. Plant J 60:1-9

Rodrigues JCM, Cabral GB, Dusi DMA, Mello LV, Rigden D, Carneiro VTC (2003) Identification of differentially expressed cDNA sequences in ovaries of sexual and apomictic plants of Brachiaria brizantha. Plant Mol Biol 53:745-757

Rodriguez-Leal D, Vielle-Calzada J-P (2012) Regulation of apomixis: learning from sexual experience. Curr Opin Plant Biol 15(5):549-555

Rozen S, Skaletsky JH (2000) Primer3 on the WWW for general users and for biologist programmers In: Krawetz $\mathrm{S}$ MSe, editor. Bioinformatics methods and protocols: methods in molecular biology. Totowa: Humana Press, pp 365-386

Saitou N, Nei M (1987) The neighbor-joining method: a new method for reconstructing phylogenetic trees. Mol Biol Evol 4:406-425

Sambrook J, Russell DW (2001) Molecular cloning: a laboratory manual. Cold Spring Harbor Laboratory Press, Cold Spring Harbor, New York

Sharbel TF, Voigt M-L, Corral JM, Galla G, Kumlehn J, Klukas C, Schreiber F, Vogel H, Rotter B (2010) Apomictic and sexual ovules of Boechera display heterochronic global gene expression patterns. Plant Cell 22:655-671

Silveira ED, Alves-Ferreira M, GuimarãeS LA, da Silva FR, Carneiro VTC (2009) Selection of reference genes for quantitative real-time PCR expression studies in the apomictic and sexual grass Brachiaria brizantha. BMC Plant Biol 9:84

Silveira ED, Guimarães LA, Dusi DMA, da Silva FR, Martins NF, do Carmo Costa M, Alves-Ferreira M, Carneiro VTC (2012) Expressed sequence-tag analysis of ovaries of Brachiaria brizantha reveals genes associated with the early steps of embryo sac differentiation of apomictic plants. Plant Cell Rep 31(2):403-16

Simon P (2003) Q-gene: processing quantitative real-time RT-PCR data. Bioinformatics 19:1439-1440

Singh M, Goel S, Meeley RB, Dantec C, Parrinello H, Michaud C, Leblanc O, Grimanelli D (2011) Production of viable gametes without meiosis in maize deficient for an ARGONAUTE protein. Plant Cell 23:443-458

Song J-J, Ma W, Tang Y-J, Chen Z-Y, Liao J-P (2010) Isolation and characterization of three MADS-box genes from Alpinia hainanensis (Zingiberaceae). Plant Mol Biol Rep 28(2):264276

Southerton SG, Marshall H, Mouradov A, Teasdale RD (1998) Eucalypt MADS-box genes expressed in developing flowers. Plant Physiol 118:365-372

Tamura K, Peterson D, Peterson N, Stecher G, Nei M, Kumar S (2011) MEGA5: molecular evolutionary genetics analysis using maximum likelihood, evolutionary distance, and maximum parsimony methods. Mol Biol Evol 28:2731-2739

Theissen G, Saedler H (2001) Plant biology floral quartets. Nature 409:469-471

Theissen G, Kim JT, Saedler H (1996) Classification and phylogeny of the MADS-box multigene family suggest defined roles of MADSbox gene subfamilies in the morphological evolution of eukaryotes. J Mol Evol 43:484-516

Thompson JD, Higgins DG, Gibson TJ (1994) CLUSTAL W: improving the sensitivity of progressive multiple sequence alignment through sequence weighting, position specific gap penalties and weight matrix choice. Nucleic Acids Res 22:4673-4680

Thompson BE, Bartling L, Whipple C, Hall DH, Sakai H, Schmidt R, Hake S (2009) Bearded-ear encodes a MADS box transcription factor critical for maize floral development. Plant Cell 21:25782590

Vandenbussche M, Zethof J, Royaert S, Weterings K, Gerats T (2004) The duplicated B-class heterodimer model: whorl-specific effects and complex genetic interactions in Petunia hybrida flower development. Plant Cell 16:741-754

Viaene T, Vekemans D, Becker A, Melzer S, Geuten K (2010) Expression divergence of the AGL6 MADS domain transcription factor lineage after a core eudicot duplication suggests functional diversification. BMC Plant Biol 10:148

Wang Y-Q, Melzer R, Theißen G (2010) Molecular interactions of orthologues of floral homeotic proteins from the gymnosperm Gnetum gnemon provide a clue to the evolutionary origin of 'floral quartets'. Plant J 64(2):177-190

Zahn LM, Kong H, Leebens-Mack JH, Kim S, Soltis PS, Landherr LL, Soltis DE, de Pamphilis CW, Ma H (2005) The evolution of the SEPALLATA subfamily of MADS-box genes: a preangiosperm origin with multiple duplications throughout angiosperm history. Genetics 169:2209-2223

Zhang J, Nallamilli BR, Mujahid H, Peng Z (2010) OsMADS6 plays an essential role in endosperm nutrient accumulation and is subject to epigenetic regulation in rice (Oryza sativa). Plant J 64:604-617

Zhang D, Hu C, Ouyang Y, Yao J (2012) Construction of a full-length cDNA library and analysis of expressed sequence tags from inflorescence of apomictic sabaigrass (Eulaliopsis binata). Plant Mol Biol Rep 30:46-54 